Supplement of

\title{
Quantification of peroxynitric acid and peroxyacyl nitrates using an ethane-based thermal dissociation peroxy radical chemical amplification cavity ring-down spectrometer
}

Youssef M. Taha et al.

Correspondence to: Hans D. Osthoff (hosthoff@ucalgary.ca)

The copyright of individual parts of the supplement might differ from the CC BY 4.0 License. 


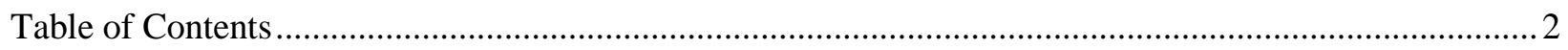

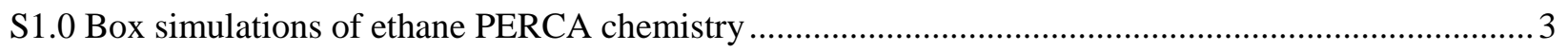

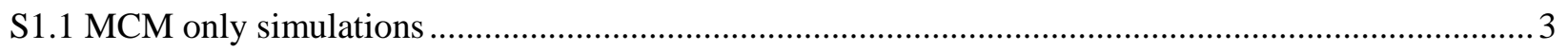

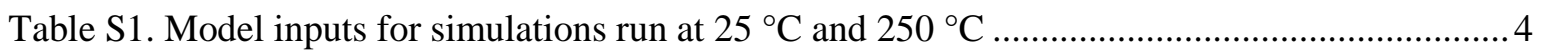

Figure S1. Time series of peroxy radicals (left-hand axis) and hydroxyl radicals (right-hand axis) for a simulation initiated with $15 \mathrm{pptv}$ of $\mathrm{HO}_{2}$ at $25^{\circ} \mathrm{C}$............................................................. 4

Figure S2. Time series of peroxy radicals (left-hand axis) and hydroxyl radicals for a simulation

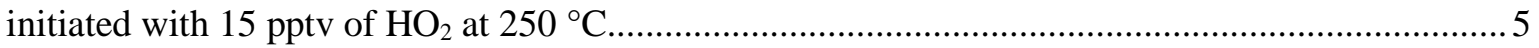

Figure S3. Time series of CL for simulations initiated with 100, 300, 600, 900, and 1200 pptv of $\mathrm{CH}_{3} \mathrm{O}_{2}$ at $25^{\circ} \mathrm{C}$ (blue colors) and $250{ }^{\circ} \mathrm{C}$ (red colors). ............................................................... 6

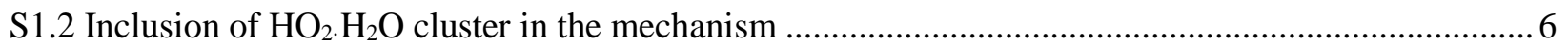

Figure S4. Time series of CL for simulations at different RH and initiated with $15 \mathrm{pptv}$ of $\mathrm{HO}_{2}$ at $25^{\circ} \mathrm{C}$ (blue colors) and $250^{\circ} \mathrm{C}$ (red colors). .......................................................................... 7

Figure S5. Time series of CL for simulations at 20\% RH initiated with different $\mathrm{HO}_{2}$ mixing ratios at $25{ }^{\circ} \mathrm{C}$ (blue colors) and $250^{\circ} \mathrm{C}$ (red colors). ......................................................................... 7

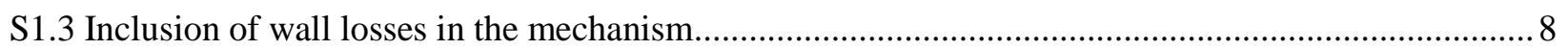

Figure S6. Time series of CL for simulations at $20 \% \mathrm{RH}$ initiated as a function of $\mathrm{HO}_{2}$ mixing ratios at $25^{\circ} \mathrm{C}$ (blue colors) and $250{ }^{\circ} \mathrm{C}$ (red colors) with $\mathrm{k}_{\text {wall }}\left(\mathrm{HO}_{2}\right)$ and $\mathrm{k}_{\text {wall }}\left(\mathrm{RO}_{2}\right)$ of $2.8 \mathrm{~s}^{-1}$ and $0.8 \mathrm{~s}^{-1}$,

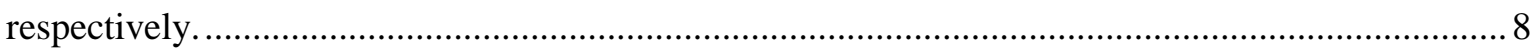

S1.4 Inclusion of ethyl nitrite formation in the mechanism.................................................................... 9

Figure S7. Same as Figure S6 but with $\mathrm{C}_{2} \mathrm{H}_{5} \mathrm{ONO}$ formation and thermal decomposition included

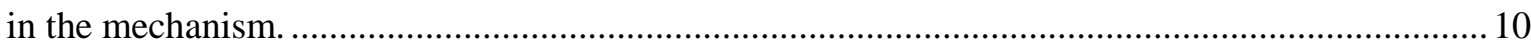

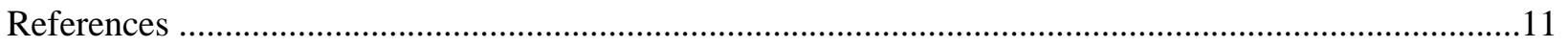




\section{S1.0 Box simulations of ethane PERCA chemistry}

Box model simulations were carried out using a subset of reactions in the "Master Chemical Mechanism" (MCM) (Jenkin et al., 1997; Saunders et al., 2003; Jenkin et al., 2012) to aid in the interpretation of experimental data and are not intended as accurate representations of experiments. To reproduce the experimental data in PERCA reaction chambers, models need to make assumptions about the magnitudes and temperature dependencies of wall loss rates (which are not known). An additional limitation is that the MCM has only been validated at ambient temperature and below, and the rate constants are more uncertain at elevated temperatures. In addition, thermal gradients within the PERCA chambers are not taken into account. Thus, simulations are poor a priori predictors of experimental chain lengths and should not be viewed as such.

In section S1.1 below, we carried out simulations using only a subset of reactions in the MCM to probe the temperature dependence of gas-phase reactions. In section S1.2, we added pseudo first-order loss rates for $\mathrm{OH}$ and $\mathrm{RO}_{2}$ radicals to simulate the potential effects of inner walls of the PERCA reactor. In section S1.3, we investigated the humidity dependence of PERCA, adding $\mathrm{HO}_{2} \cdot \mathrm{H}_{2} \mathrm{O}$ chemistry using the equilibrium constants by Kanno et al. (2006) and the reactions of $\mathrm{HO}_{2} \cdot \mathrm{H}_{2} \mathrm{O}$ with $\mathrm{HO}_{2}$ (Kanno et al., 2006) and NO (Butkovskaya et al., 2007). Finally, in section S1.4, we considered formation of ethyl nitrite and ethyl peroxy nitrate, which are not part of the MCM.

\section{S1.1 MCM only simulations}

The chemistry in the PERCA reactor was modelled at temperatures of $25^{\circ} \mathrm{C}$ or $250{ }^{\circ} \mathrm{C}$ using a subset of the MCM V3.3.1 obtained from http://mcm.leeds.ac.uk/MCM by adding ethane to the marked list and extracting the subset in the Kinetic Preprocessor (KPP) (Sandu and Sander, 2006) format along with inorganic reactions and generic rate coefficients. A plug flow modelling approach was used where initial conditions and mixing ratios were set and the model allowed to proceed without any additional inputs or outputs. Radical wall-loss reactions were not added.

Simulations were performed using the optimized PERCA reagent gas concentrations (i.e., 650 ppbv NO; $1.65 \%$ ethane) at either $25{ }^{\circ} \mathrm{C}$ or $250^{\circ} \mathrm{C}$. Table S1 provides an overview of the model inputs. The model runs were also initialized with an initial input of 15, 100, 300, 600, 900, or 1200 pptv of either $\mathrm{HO}_{2}$ or $\mathrm{CH}_{3} \mathrm{O}_{2}$. 
Table S1. Model inputs for simulations run at $25^{\circ} \mathrm{C}$ and $250{ }^{\circ} \mathrm{C}$

\begin{tabular}{|c|c|c|c|}
\hline & Mixing Ratio & $\begin{array}{c}\text { Number density at } 25^{\circ} \mathrm{C} \\
\left(\text { molecules } \mathrm{cm}^{-3}\right)\end{array}$ & $\begin{array}{c}\text { Number density at } 250{ }^{\circ} \mathrm{C} \\
\left(\text { molecules } \mathrm{cm}^{-3}\right)\end{array}$ \\
\hline $\mathrm{M}$ & - & $2.14 \times 10^{19}$ & $1.22 \times 10^{19}$ \\
\hline $\mathrm{NO}$ & 650 ppbv & $1.39 \times 10^{13}$ & $7.92 \times 10^{12}$ \\
\hline $\mathrm{C}_{2} \mathrm{H}_{6}$ & $1.65 \%$ & $3.53 \times 10^{17}$ & $2.01 \times 10^{17}$ \\
\hline $\mathrm{O}_{2}$ & $20.1 \%$ & $4.29 \times 10^{18}$ & $2.45 \times 10^{18}$ \\
\hline $\mathrm{N}_{2}$ & $77.6 \%$ & $1.66 \times 10^{19}$ & $9.46 \times 10^{18}$ \\
\hline
\end{tabular}

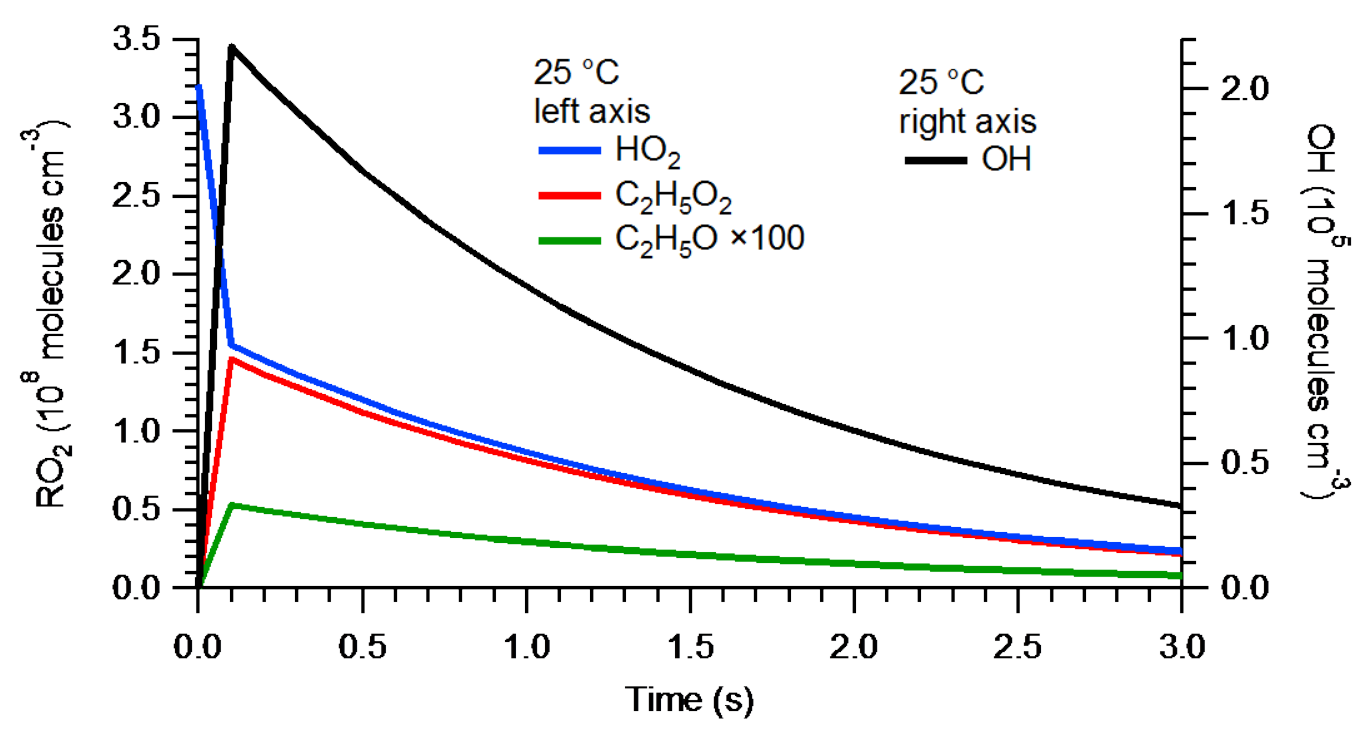

Figure S1. Time series of peroxy radicals (left-hand axis) and hydroxyl radicals (right-hand axis) for a simulation initiated with 15 pptv of $\mathrm{HO}_{2}$ at $25^{\circ} \mathrm{C}$. 


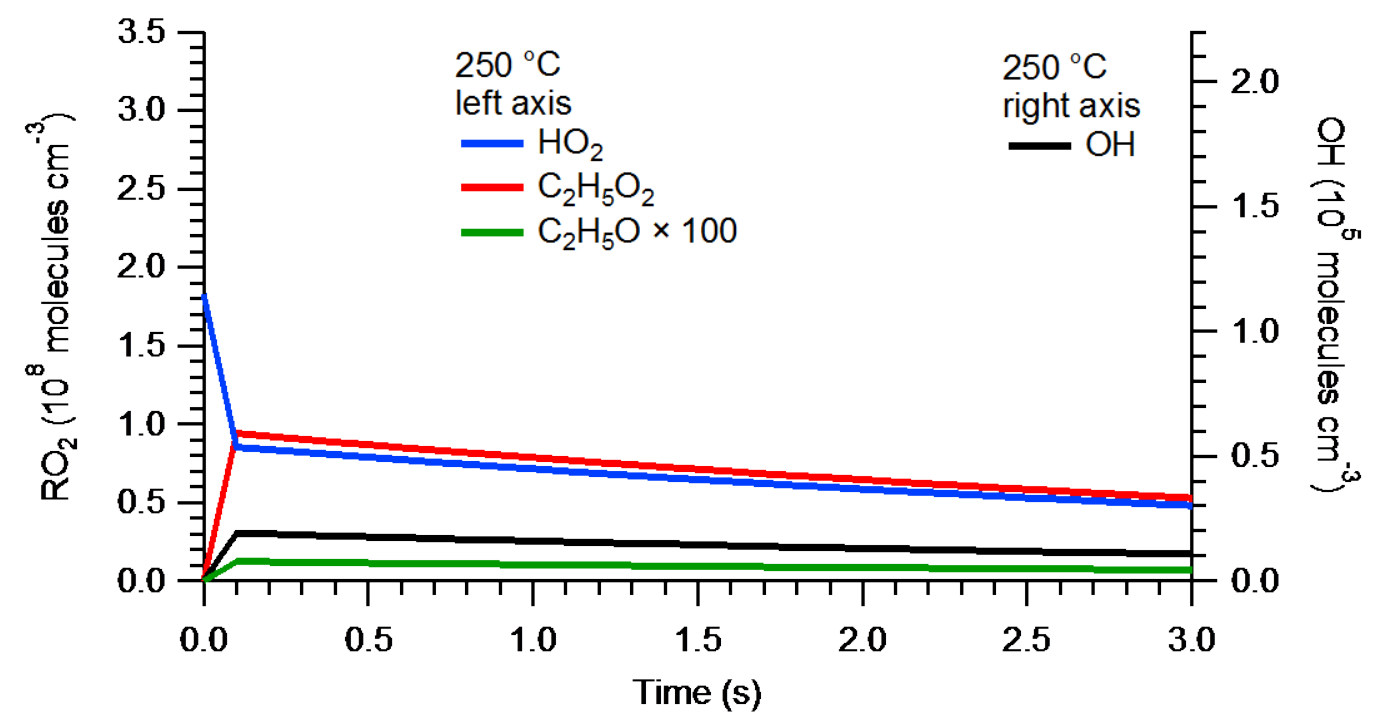

Figure S2. Time series of peroxy radicals (left-hand axis) and hydroxyl radicals for a simulation initiated with 15 pptv of $\mathrm{HO}_{2}$ at $250{ }^{\circ} \mathrm{C}$.

Figures S1 and S2 show peroxy and hydroxyl radical concentrations during the first 5 seconds of simulations initiated with $15 \mathrm{pptv}$ of $\mathrm{HO}_{2}$ at $25^{\circ} \mathrm{C}$ and $250^{\circ} \mathrm{C}$, respectively. In our chamber, the PERCA reactions are stopped as the radicals encounter the filter after $2.3 \mathrm{~s}$ in the dual channel setup. Due to the lower gas density at higher temperatures, a lower concentration of $\mathrm{RO}_{2}$ radicals is present initially (even though the mixing ratio is the same in both cases). Reactions of $\mathrm{HO}_{2}$ and $\mathrm{RO}_{2}$ with $\mathrm{NO}$ (e.g., R3, Table 2 of the main manuscript) have negative activation energies and are hence slower at higher temperatures, leading to a lower rate of $\mathrm{OH}$ radical production and, since $\mathrm{OH}$ loss rates are similar, to lower $\mathrm{OH}$ concentrations (maximum of $\sim 1.9 \times 10^{4}$ molecules $\mathrm{cm}^{-3}$ at $250^{\circ} \mathrm{C}$ vs. $2.2 \times 10^{5}$ molecules $\mathrm{cm}^{-3}$ at $25^{\circ} \mathrm{C}$ ) and lower turnover numbers.

Figure S3 shows the $\mathrm{CL}$ (number of $\mathrm{NO}_{2}$ molecules produced divided by molecules of $\mathrm{RO}_{2}$ present originally) as a function of temperature and mixing ratio of radicals added initially. Simulations initiated with $\mathrm{HO}_{2}$ radicals gave identical results to simulations initiated with $\mathrm{CH}_{3} \mathrm{O}_{2}$ radicals. For simulations conducted at $25^{\circ} \mathrm{C}$, CL is concentration dependent and decrease with increasing concentration. For simulations conducted at $250{ }^{\circ} \mathrm{C}$, the chain length is still concentration dependent, albeit to a much lesser extent than at room temperature. At $250^{\circ} \mathrm{C}$, the $\mathrm{CL}$ in the initial $2.3 \mathrm{~s}$ of reaction time is well below the CL obtained at $25^{\circ} \mathrm{C}$, inconsistent with experiment which showed a CL of $69 \pm 5$ at $250{ }^{\circ} \mathrm{C}$ (much higher than CL obtained at $25{ }^{\circ} \mathrm{C}$. This suggests that experimental CL are largely a function of wall reactions not included in the simulations. 


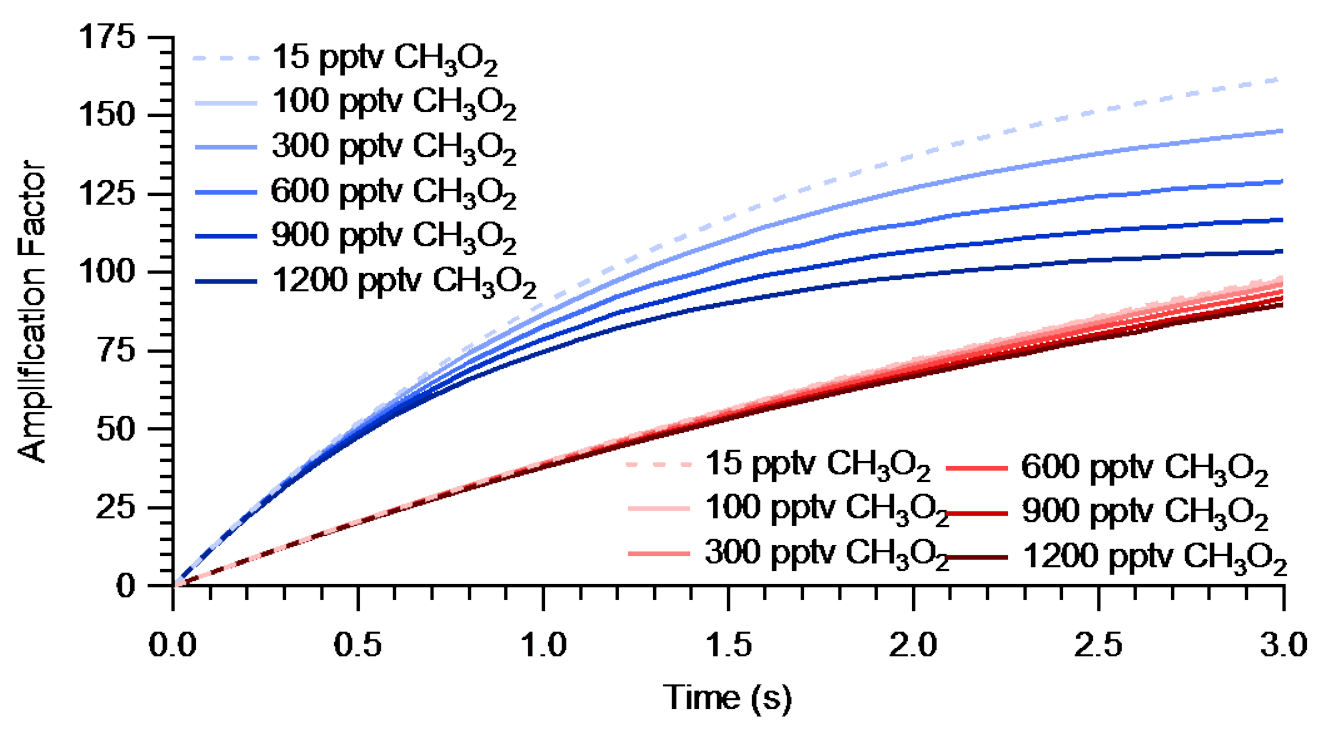

Figure S3. Time series of CL for simulations initiated with 100, 300, 600, 900, and $1200 \mathrm{pptv}$ of $\mathrm{CH}_{3} \mathrm{O}_{2}$ at $25^{\circ} \mathrm{C}$ (blue colors) and $250{ }^{\circ} \mathrm{C}$ (red colors).

\section{S1.2 Inclusion of $\mathrm{HO}_{2} \cdot \mathrm{H}_{2} \mathrm{O}$ cluster in the mechanism}

Another factor contributing to observed CL are radical losses due to $\mathrm{HO}_{2}$ water cluster formation (i.e., $\mathrm{HO}_{2} \cdot \mathrm{H}_{2} \mathrm{O}$ ) (Kanno et al., 2006). To estimate the temperature dependent formation of $\mathrm{HO}_{2} \cdot \mathrm{H}_{2} \mathrm{O}$ cluster the model assumed that equilibrium between the cluster and $\mathrm{HO}_{2}$ and $\mathrm{H}_{2} \mathrm{O}$ was established at every model time step (0.1 s) following the equilibrium rate constant reported by Kanno et al. (2006): $6.6 \times 10^{-17} \times \mathrm{T} \times \mathrm{e}^{(3700 / \mathrm{T})}$. Upon formation, $\mathrm{HO}_{2} \cdot \mathrm{H}_{2} \mathrm{O}$ can react with $\mathrm{HO}_{2}\left(\mathrm{k}=6.0 \times 10^{-13} \mathrm{~cm}^{3}\right.$ molecule $\left.{ }^{-1} \mathrm{~s}^{-1}\right)$ (Kanno et al., 2006) or NO $\left(\mathrm{k}=5.4 \times 10^{-11} \mathrm{e}^{(-410 / \mathrm{T})} \mathrm{cm}^{3}\right.$ molecule $\mathrm{e}^{-1} \mathrm{~s}^{-1}$ ) (Butkovskaya et al., 2007; Butkovskaya et al., 2009).

Figure S4 shows the CL obtained after the inclusion of $\mathrm{HO}_{2} \cdot \mathrm{H}_{2} \mathrm{O}$ cluster as a function of $\mathrm{RH}$ at $25{ }^{\circ} \mathrm{C}$ and $250{ }^{\circ} \mathrm{C}$ initiated with $15 \mathrm{pptv} \mathrm{HO}_{2}$. At $25^{\circ} \mathrm{C}$, the $\mathrm{CL}$ is strongly dependent on $\mathrm{RH}$, whereas at $250{ }^{\circ} \mathrm{C}$, there is very little $\mathrm{RH}$ dependence as the $\mathrm{HO}_{2} \cdot \mathrm{H}_{2} \mathrm{O}$ cluster is thermally dissociated.

Figure S5 shows the concentration dependence at a RH of $20 \%$ after inclusion of water clusters in the model simulations. Ultimately, lower CL are observed in the $25{ }^{\circ} \mathrm{C}$ system while the $250{ }^{\circ} \mathrm{C}$ system chemistry, and associated CL, are relatively unchanged. Furthermore, CLs in the initial $2.3 \mathrm{~s}$ of reaction time were generally well below CL obtained at the lower temperature. Once again, this is inconsistent with our experiments where elevated temperatures provided for larger CL values. 


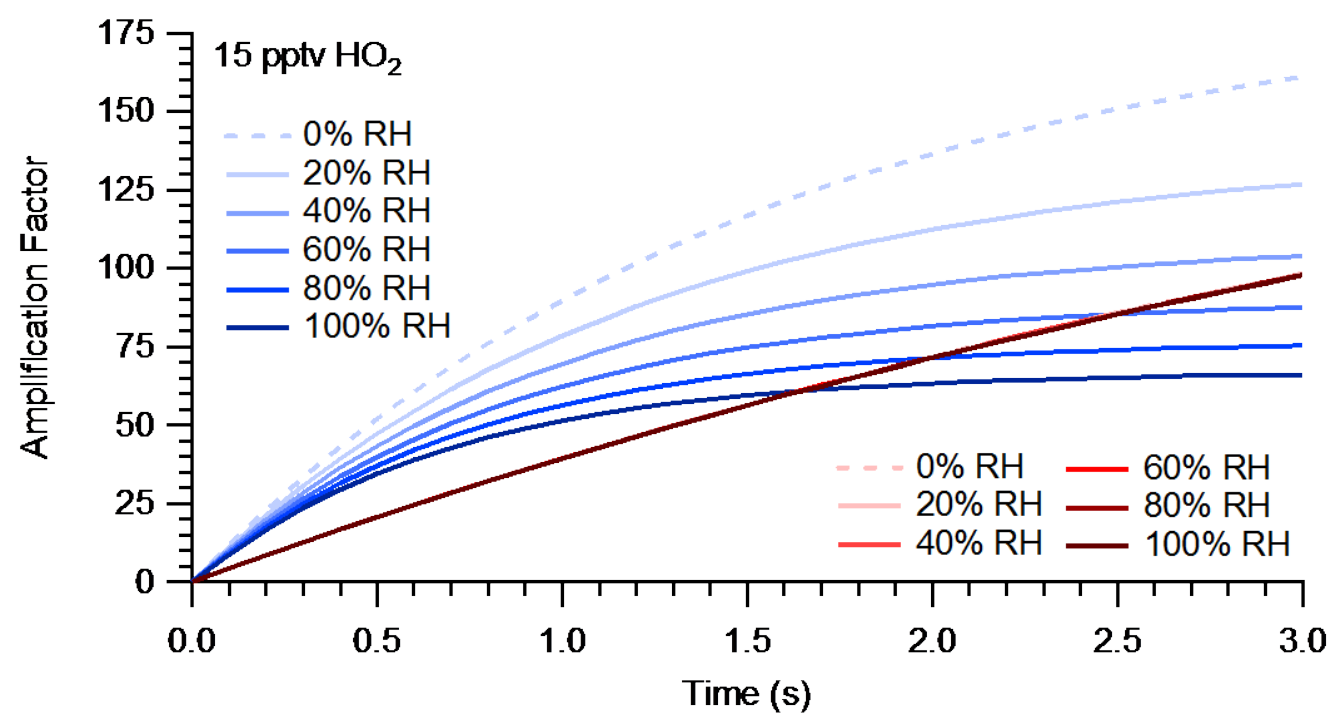

Figure S4. Time series of CL for simulations at different RH and initiated with 15 pptv of $\mathrm{HO}_{2}$ at 25 ${ }^{\circ} \mathrm{C}$ (blue colors) and $250{ }^{\circ} \mathrm{C}$ (red colors).

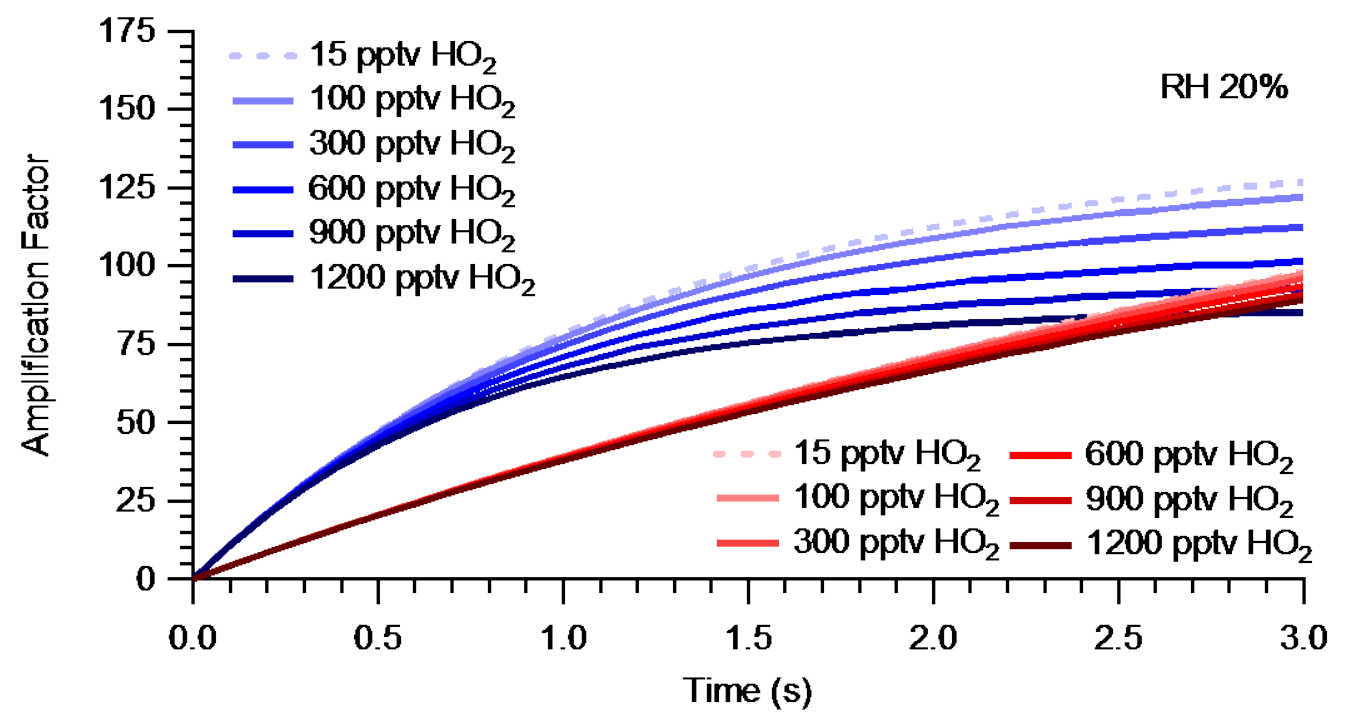

Figure S5. Time series of $\mathrm{CL}$ for simulations at $20 \% \mathrm{RH}$ initiated with different $\mathrm{HO}_{2}$ mixing ratios at $25^{\circ} \mathrm{C}$ (blue colors) and $250{ }^{\circ} \mathrm{C}$ (red colors). 


\section{S1.3 Inclusion of wall losses in the mechanism}

The dependence of CL on temperature and RH in the model simulations shown in S1 and S2 are inconsistent with experiment. To reconcile model simulations with experiment, pseudo-first order wall loss reactions of radicals were added to the mechanism. The room-temperature rate constants reported by Mihele et al. (1999) for $\mathrm{HO}_{2}$ and $\mathrm{RO}_{2}$ of $2.8 \mathrm{~s}^{-1}$ and $0.8 \mathrm{~s}^{-1}$ were used, respectively.

Figure S6 shows a time series of the CL for simulations conducted at 20\% RH after inclusion of these wall losses in the model. Due to increased radical losses, radical chemistry ceases after $\sim 1$ s. Furthermore, the CL dependence on radical concentration is reduced.

Inconsistent with experiment, the $\mathrm{CL}$ is still predicted to be larger at $25^{\circ} \mathrm{C}$ than at $250{ }^{\circ} \mathrm{C}$. This may be a result of the use of temperature independent wall loss rates that should be reduced at elevated temperatures. Assuming, as a lower limit, no wall losses at $250^{\circ} \mathrm{C}$, and factoring in the 2.3 second residence time of our PERCA chamber, the simulations predict larger CL at elevated temperatures (a CL of 80 at $250{ }^{\circ} \mathrm{C}$ and a CL of 44 at $25^{\circ} \mathrm{C}$ - shown as a green trace in Fig. S6).

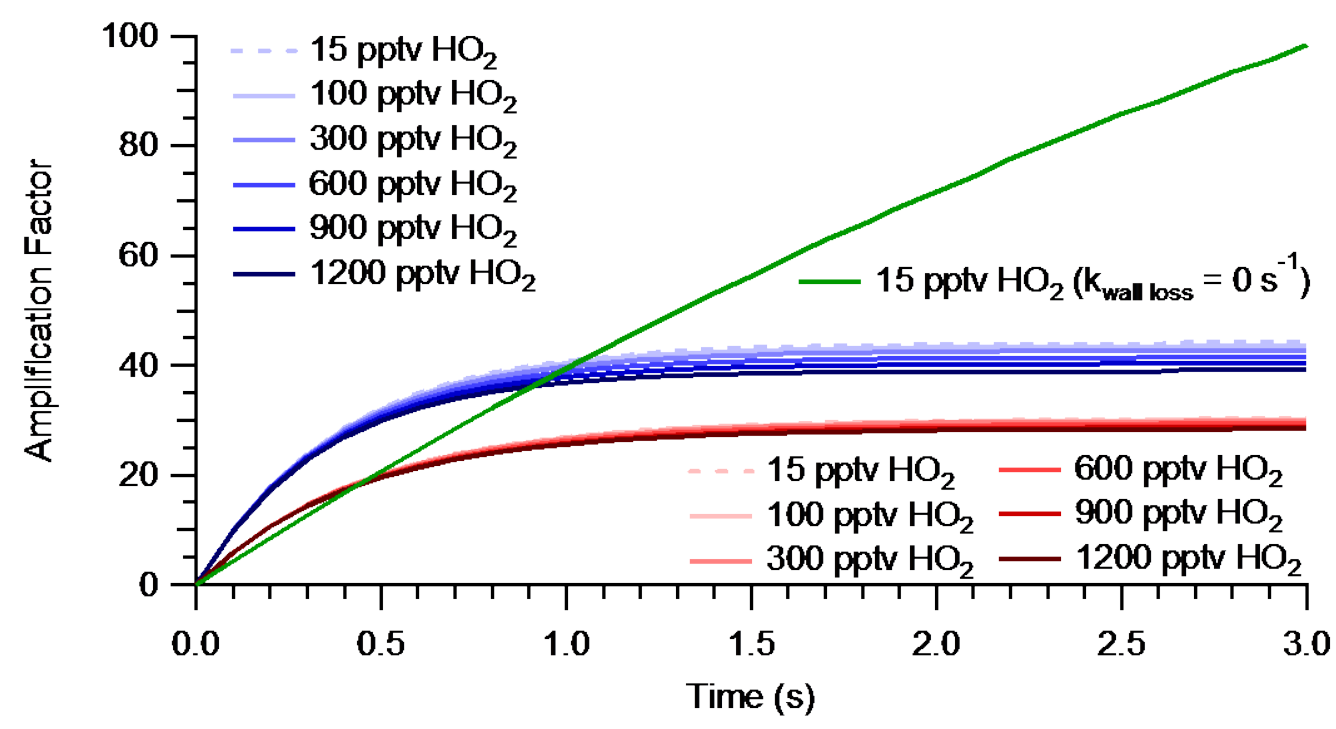

Figure S6. Time series of CL for simulations at $20 \% \mathrm{RH}$ initiated as a function of $\mathrm{HO}_{2}$ mixing ratios at $25^{\circ} \mathrm{C}$ (blue colors) and $250{ }^{\circ} \mathrm{C}$ (red colors) with $\mathrm{k}_{\text {wall }}\left(\mathrm{HO}_{2}\right)$ and $\mathrm{k}_{\text {wall }}\left(\mathrm{RO}_{2}\right)$ of $2.8 \mathrm{~s}^{-1}$ and $0.8 \mathrm{~s}^{-1}$, respectively. 


\section{S1.4 Inclusion of ethyl nitrite and ethyl peroxy nitrate formation in the mechanism}

A potentially important radical chain termination reaction not included in the $\mathrm{MCM}$ is that between $\mathrm{C}_{2} \mathrm{H}_{5} \mathrm{O}$ and NO to form $\mathrm{C}_{2} \mathrm{H}_{5} \mathrm{ONO}$ (Mihele and Hastie, 2000; Wood et al., 2016). The rate of this reaction decreases slightly with temperature: At a pressure of 660 Torr and using kinetic parameters from (Burkholder et al., 2015), the rate coefficient decreases from $4.8 \times 10^{-11}$ to $3.9 \times 10^{-11} \mathrm{~cm}^{3}$ molecule ${ }^{-1} \mathrm{~s}^{-1}$ between $25^{\circ} \mathrm{C}$ and 250

${ }^{\circ} \mathrm{C}$. Ethyl nitrite thermally decomposes with an activation barrier of $\sim 157 \mathrm{~kJ} \mathrm{~mol}^{-1}$ (Steacie and Shaw, 1934) and has a lifetime with respect to thermal decomposition (to $\mathrm{NO}$ and $\mathrm{C}_{2} \mathrm{H}_{5} \mathrm{O}$ ) of $\sim 40 \mathrm{~s}$ at $250{ }^{\circ} \mathrm{C}$; this implies that for the temperature ranges shown in the manuscript, ethyl nitrite will not significantly decompose and constitutes a radical sink.

Another potentially important radical chain termination reaction not included in the MCM is that between $\mathrm{C}_{2} \mathrm{H}_{5} \mathrm{O}_{2}$ and $\mathrm{NO}_{2}$ to form $\mathrm{C}_{2} \mathrm{H}_{5} \mathrm{O}_{2} \mathrm{NO}_{2}$ (Wood et al., 2016). The rate of this reaction also decreases slightly with temperature: at a pressure of 660 Torr and using the kinetic parameters from (Burkholder et al., 2015), the rate coefficient decreases from $8.8 \times 10^{-12}$ to $8.5 \times 10^{-12} \mathrm{~cm}^{3}$ molecule $\mathrm{s}^{-1} \mathrm{~s}^{-1}$ between $25^{\circ} \mathrm{C}$ and $250{ }^{\circ} \mathrm{C}$. $\mathrm{C}_{2} \mathrm{H}_{5} \mathrm{O}_{2} \mathrm{NO}_{2}$ thermally decomposes with an activation barrier of $\sim 86.8 \mathrm{~kJ} \mathrm{~mol}^{-1}$ and has lifetimes with respect to thermal decomposition (to $\mathrm{NO}_{2}$ and $\mathrm{C}_{2} \mathrm{H}_{5} \mathrm{O}_{2}$ ) of $\sim 0.2 \mathrm{~s}$ and $\sim 5 \times 10^{-8} \mathrm{~s}$ at $25^{\circ} \mathrm{C}$ and $250{ }^{\circ} \mathrm{C}$, respectively. Formation of this molecule is hence expected to shift radical chemistry at $25^{\circ} \mathrm{C}$ while having little effect at $250^{\circ} \mathrm{C}$.

Shown in Figure S7 are the simulations of Figure S6 with $\mathrm{C}_{2} \mathrm{H}_{5} \mathrm{ONO}$ and $\mathrm{C}_{2} \mathrm{H}_{5} \mathrm{O}_{2} \mathrm{NO}_{2}$ formation and thermal decomposition added to the mechanism.

Assuming, as a lower limit, no wall losses at $250^{\circ} \mathrm{C}$, and factoring in the 2.3 s residence time of our PERCA chamber, the simulations predict larger CL at elevated temperatures (a CL of 65 at $250{ }^{\circ} \mathrm{C}$ and a CL of 30 at $25^{\circ} \mathrm{C}$ - shown as a green trace in Fig. S6). These values are consistent with experiment. 


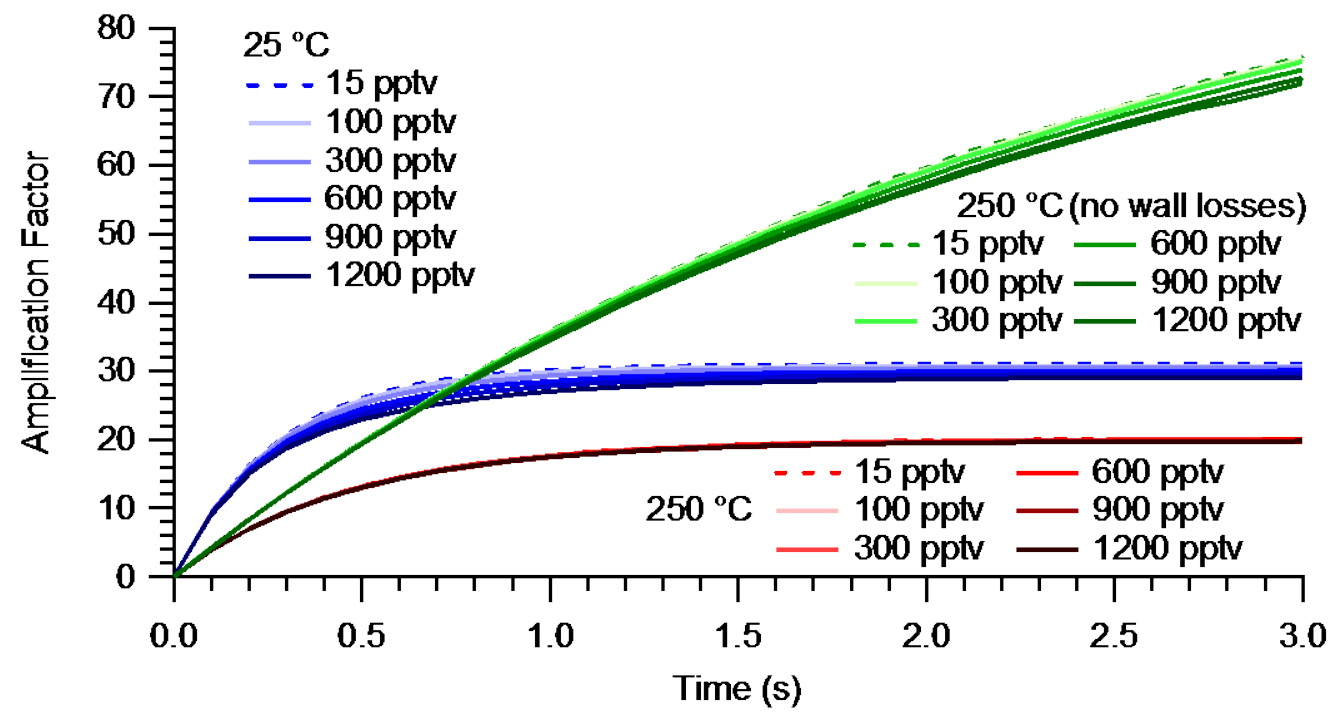

Figure S7. Same as Figure $\mathrm{S} 6$ but with $\mathrm{C}_{2} \mathrm{H}_{5} \mathrm{ONO}$ and $\mathrm{C}_{2} \mathrm{H}_{5} \mathrm{O}_{2} \mathrm{NO}_{2}$ formation and thermal decomposition included in the mechanism. 


\section{References}

Burkholder, J. B., Sander, S. P., Abbatt, J. P. D., Barker, J. R., Huie, R. E., Kolb, C. E., Kurylo, M. J., Orkin, V. L., Wilmouth, D. M., and Wine, P. H.: Chemical Kinetics and Photochemical Data for Use in Atmospheric Studies, Evaluation Number 18, National Aeronautics and Space Administration, Jet Propulsion Laboratory, California Institute of Technology, Pasadena, California, 2015.

Butkovskaya, N., Kukui, A., and Le Bras, G.: $\mathrm{HNO}_{3}$ forming channel of the $\mathrm{HO}_{2}+\mathrm{NO}$ reaction as a function of pressure and temperature in the ranges of 72-600 Torr and 223-323 K, J. Phys. Chem. A, 111, 90479053, 10.1021/jp074117m, 2007.

Butkovskaya, N., Rayez, M. T., Rayez, J. C., Kukui, A., and Le Bras, G.: Water Vapor Effect on the $\mathrm{HNO}_{3}$ Yield in the $\mathrm{HO}_{2}+$ NO Reaction: Experimental and Theoretical Evidence, J. Phys. Chem. A, 113, 11327-11342, 10.1021/jp811428p, 2009.

Jenkin, M. E., Saunders, S. M., and Pilling, M. J.: The tropospheric degradation of volatile organic compounds: a protocol for mechanism development, Atmos. Environm., 31, 81-104, 10.1016/S13522310(96)00105-7, 1997.

Jenkin, M. E., Wyche, K. P., Evans, C. J., Carr, T., Monks, P. S., Alfarra, M. R., Barley, M. H., McFiggans, G. B., Young, J. C., and Rickard, A. R.: Development and chamber evaluation of the MCM v3.2 degradation scheme for $\beta$-caryophyllene, Atmos. Chem. Phys., 12, 5275-5308, 10.5194/acp-12-5275-2012, 2012.

Kanno, N., Tonokura, K., and Koshi, M.: Equilibrium constant of the $\mathrm{HO}_{2}-\mathrm{H}_{2} \mathrm{O}$ complex formation and kinetics of $\mathrm{HO}_{2}+\mathrm{HO}_{2}-\mathrm{H}_{2} \mathrm{O}$ : Implications for tropospheric chemistry, J. Geophys. Res.-Atmos., 111, D20312, 10.1029/2005jd006805, 2006.

Mihele, C. M., Mozurkewich, M., and Hastie, D. R.: Radical loss in a chain reaction of CO and NO in the presence of water: Implications for the radical amplifier and atmospheric chemistry, Internat. J. Chem. Kin., 31,145-152, 10.1002/(sici)1097-4601(1999)31:2<145::aid-kin7>3.0.co;2-m, 1999.

Mihele, C. M., and Hastie, D. R.: Optimized operation and calibration procedures for radical amplifier-type detectors, Journal Of Atmospheric And Oceanic Technology, 17, 788-794, 10.1175/15200426(2000)017<0788:OOACPF>2.0.CO;2, 2000.

Sandu, A., and Sander, R.: Technical note: Simulating chemical systems in Fortran90 and Matlab with the Kinetic PreProcessor KPP-2.1, Atmos. Chem. Phys., 6, 187-195, 10.5194/acp-6-187-2006, 2006. 
Saunders, S. M., Jenkin, M. E., Derwent, R. G., and Pilling, M. J.: Protocol for the development of the Master Chemical Mechanism, MCM v3 (Part A): tropospheric degradation of non-aromatic volatile organic compounds, Atmos. Chem. Phys., 3, 161-180, 10.5194/acp-3-161-2003, 2003.

Steacie, E. W. R., and Shaw, G. T.: The Homogeneous Unimolecular Decomposition of Gaseous Alkyl Nitrites. II. The Decomposition of Ethyl Nitrite, The Journal of Chemical Physics, 2, 345-348, 10.1063/1.1749485, 1934.

Wood, E. C., Deming, B. L., and Kundu, S.: Ethane-Based Chemical Amplification Measurement Technique for Atmospheric Peroxy Radicals, Environmental Science \& Technology Letters, 4, 15-19, 10.1021/acs.estlett.6b00438, 2016. 